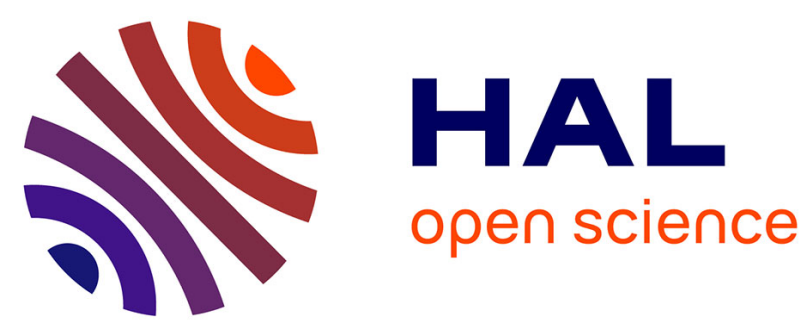

\title{
Serial multiple crossed immunoelectrophoresis at a micro scale: A stamp-sized 2D immunoanalysis of protein C3 activation caused by nanoparticles
}

Jean-Baptiste Coty, Fanny Varenne, Jean-Jacques Vachon, Christine Vauthier

\section{- To cite this version:}

Jean-Baptiste Coty, Fanny Varenne, Jean-Jacques Vachon, Christine Vauthier. Serial multiple crossed immunoelectrophoresis at a micro scale: A stamp-sized 2D immunoanalysis of protein C3 activation caused by nanoparticles. Electrophoresis, 2016, 37 (17-18), pp.2401 - 2409. 10.1002/elps.201500572 . hal-03199949

\section{HAL Id: hal-03199949 \\ https://hal.science/hal-03199949}

Submitted on 16 Apr 2021

HAL is a multi-disciplinary open access archive for the deposit and dissemination of scientific research documents, whether they are published or not. The documents may come from teaching and research institutions in France or abroad, or from public or private research centers.
L'archive ouverte pluridisciplinaire HAL, est destinée au dépôt et à la diffusion de documents scientifiques de niveau recherche, publiés ou non, émanant des établissements d'enseignement et de recherche français ou étrangers, des laboratoires publics ou privés. 


\title{
Serial multiple crossed immunoelectrophoresis at a micro scale: a stamp-size 2D immunoanalysis of protein C3 activation caused by nanoparticles
}

\author{
Jean-Baptiste Coty, Fanny Varenne, Jean-Jacques Vachon, Christine Vauthier* \\ Institut Galien Paris-Sud, CNRS, Univ. Paris-Sud, Université Paris-Saclay, 5 rue Jean-Baptiste Clément, \\ 92290 Châtenay-Malabry, France
}

\begin{abstract}
*Correspondence: Dr. Christine Vauthier, CNRS UMR 8612, Institut Galien Paris Sud, Univ. Paris-Sud, Université Paris-Saclay, 5, rue Jean-Baptiste Clément, 92296 Châtenay-Malabry, France. Fax: +33 146835946. E-mail: christine.vauthier@u-psud.fr
\end{abstract}

Published in: Electrophoresis 2016, 37, 2401-2409. https://doi.org/10.1002/elps.201500572

\begin{abstract}
:
Crossed immunoelectrophoresis (C-IE) is used to detect and quantify specific proteins. An application allowed the evaluation of complement system activation by nanomaterials. The work aimed to improve the C-IE toward a higher throughput and less tedious method. A new concept was implemented to prepare and run agarose gels. The $1^{\text {st }}$ and the $2^{\text {nd }}$ dimension of electrophoresis were performed on a single gel plate, prepared before the beginning of the analysis. Several samples were migrated simultaneously on the same migration line. Up to 35 analyses were run at once, providing stamp-sized electrophoregrams $(2.8 \times 3 \mathrm{~cm})$ maintaining the performance of the original method performed on $5 \times 7 \mathrm{~cm}$ gel slabs. Robustness and precision of the method were demonstrated through a validation approach using ANOVA. Handling, experimental duration, amount of reagents and overall cost of one analysis were considerably reduced compared to the original method. With the same equipment, 7 times more analyses can be performed in one run. C-IE can be used to analyze many types of proteins. The new experimental modalities were suitable for the application developed in the present work that was to evaluate activation of protein C3 of the complement system triggered by nanomaterials
\end{abstract}

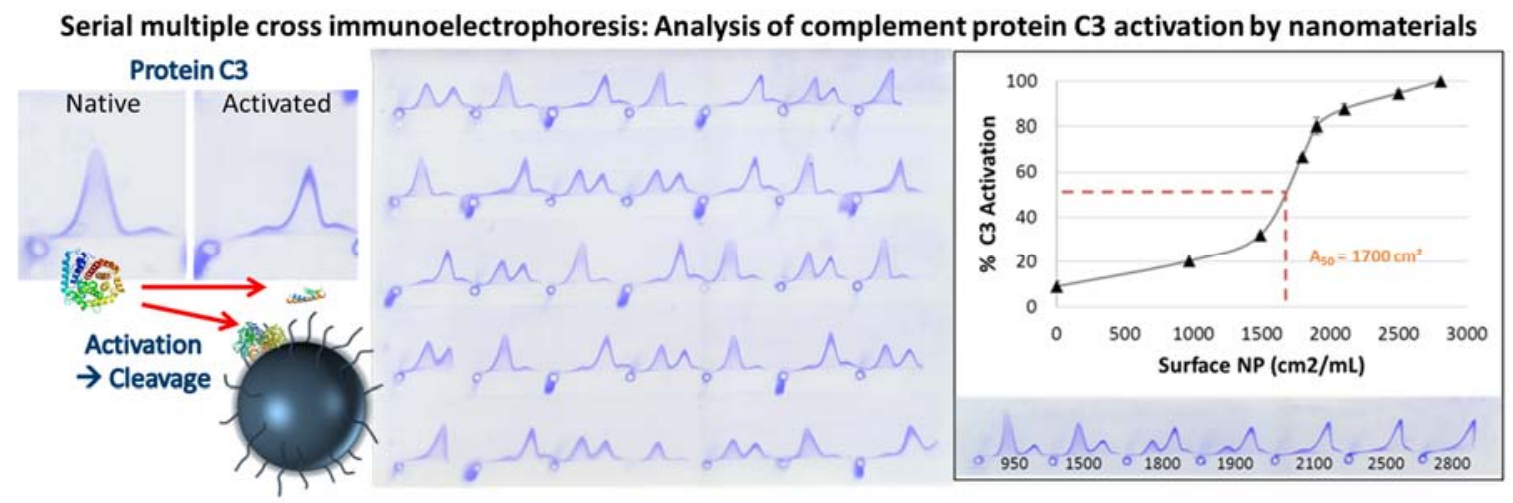




\section{Abbreviations:}

2D-IE: Two-dimensional immunoelectrophoresis, ANOVA: Analysis of Variance, $\mathrm{C}_{3} \mathrm{~A}_{50}$ : Protein $\mathrm{C} 3$ activation at $50 \%$, CARPA: Complement Activation Related PseudoAllergy,

C-IE: Crossed immunoelectrophoresis,

$\mathrm{D}_{\mathrm{H}}$ : Hydrodynamic diameter,

DLS: Dynamic light scattering,

ELS: Electrophoresis light scattering,

EP: Emulsion polymerization,

GUM: guide to the expression of uncertainty in measurement,

IBCA: Isobutylcyanoacrylate,

ICH: International Conference on Harmonisation of Technical Requirements for Registration of Pharmaceuticals for Human Use,

ISO: International Organization for Standardization,

NM: Nafamostat Mesylate,

$N P(s)$ : Nanoparticle(s),

$M_{c}$ : Mass concentration,

Sc: Surface concentration,

VBS: Veronal Buffer Saline,

MultiCrossed-IE: Serial multiple crossed immunoelectrophoresis at a micro scale

Keywords: Complement system, crossed immunoelectrophoresis, protein C3, robustness 


\section{Introduction}

It is now quite well established that nanomaterials circulating in the blood, either intentionally when used as nanomedicines, or accidentally after exposition to pollutants, are subjected to recognition by the immune system [1-3]. Although still not fully established, it seems that the activation of the complement system may be one of the first event responsible for the clearance of nanomaterials from the blood, associated with uptake by macrophages of the immune system [4]. The complement system is also at the root of hypersensitivity and allergic reactions. Among them, the development of Complement Activation Related PseudoAllergy (CARPA) that is still not entirely understood, and can have a dramatic issue for patients $[5,6]$. Thus, there is an interest to evaluate the propensity of a nanomaterial to activate the complement system, as it is one of the possible ways to assess its nanotoxicity.

In vitro tests on this purpose are well established including western blot, $\mathrm{CH} 50$ assay (Total Hemolytic Complement assay), ELISA, C-IE or immunoprecipitation tests [7-11]. Among them, the C-IE (or 2D-IE) of the complement $\mathrm{C} 3$ protein was not so much applied due to the tedious operating conditions, although it allows to reveal the cleavage of the protein C3 of the cascade in a non-debated manner [12-14]. Complement protein C3 is a protein that intervenes in the final pathway of the complement cascade, being common to all known pathways that trigger activation of the cascade [15, 16]. Measurement of protein C3 cleavage allows the assessment of complement activation, independently of the pathway triggering the activation. In the obtained electrophoregram, a first peak corresponds to native $\mathrm{C} 3$, which may partially or totally disappear after activation, to be replaced by a second and sometimes a third peak, corresponding to cleaved components of C3 [17]. The method can be applied on samples directly obtained from the incubation with the serum without the need to remove the tested nanomaterial, as it is the case with other methods such as $\mathrm{CH} 50$ assay [8] and Western Blot.

Today, there is a need for methods to the study of complement activation by a large number of nanomaterials. The demanding protocol of the C-IE hampers its development at the expense of the direct information provided from the reading and analysis of gels.

The purpose of the present work was to develop a high throughput analytical method based on C-IE, by achieving serial multiple crossed immunoelectrophoresis at a micro scale (MultiCrossed-IE) on a single agarose gel plate. Although several migrations of samples can be achieved in parallel on a gel plate, the novelty of the work was to incorporate samples to be analyzed on the same line of migration. The new approach was applied to the investigation of the activation of component C3 of the complement system triggered by three types of known nanoparticles, tested at different levels of activation. The robustness of the method was assessed by testing the influence of sample's position on the gel plate, the electrophoresis apparatus, the analyst and the sample preparation. The precision of the method was evaluated via the intra- and inter-day variation.

The method was then applied to the evaluation of the amount of NP's surface that induces a cleavage of $50 \%$ of the native $C 3$ into fragments $\left(C_{3} A_{50}\right)$. This value could be proposed as a new 
parameter characterizing nanomaterials in terms of their capacity to trigger activation of the complement system, thus breaking the limit of previous methods that only allowed comparison of few nanomaterials tested for a same concentration expressed as the exposed surface.

\section{Materials and Methods}

\subsection{Materials}

Isobutylcyanoacrylate (IBCA) was purchased from Orapi (Saint-Vulbas, France). Dextran 17.7 kDa and cerium (IV) ammonium nitrate were provided by Fluka (Saint-Quentin-Fallavier, France). Dextran 66.7 $\mathrm{kDa}$, Tricine, Tris base (Sigma 7- $9^{\circledR}$ ), Sodium chloride, EDTA sodium salt and Bromophenol blue were purchased from Sigma (Saint-Quentin-Fallavier, France). Nitric acid was supplied by Prolabo (Paris, France). Human serum was prepared from plasma provided by Etablissement Français du Sang (EFS) (Rungis, France). Polyclonal anti-human C3 antibody raised in goat was purchased from Fitzgerald antibodies (Acton, USA). Coomassie brilliant blue R-250, calcium lactate and glacial acetic acid were supplied by Thermo Fisher Scientific (Villebon-sur-Yvette, France). Gel-Fix ${ }^{\mathrm{TM}}$ for agarose $(265 \times 150$ $\mathrm{mm}$ ) was purchased from Serva Electrophoresis (Heidelberg, Germany). Nafamostat mesylate (NM) was obtained from Abcam (Cambridge, UK).

\subsection{Nanoparticle preparation and characterization}

\subsubsection{Preparation of the NPs}

NPs were prepared by emulsion polymerization (EP) adapting protocols proposed by Chauvierre et al. [18], according to Bertholon et al. [14]. The NPs R17 and R66 were obtained by redox radical EP using dextran $17.7 \mathrm{kDa}$ and $66.7 \mathrm{kDa}$ respectively. Cerium IV ammonium nitrate $\left(2 \mathrm{~mL}, 8.10^{-2} \mathrm{M}\right.$ in $\mathrm{HNO}_{3} 0.2$ $\mathrm{N})$ and IBCA $(0.5 \mathrm{~mL})$ were successively added in a solution of dextran $\left(0.136 \mathrm{~g}\right.$ in $8 \mathrm{~mL} \mathrm{HNO} \mathrm{H}_{3} 0.2 \mathrm{~N}$, $40^{\circ} \mathrm{C}$ ), purged with argon. The polymerization was pursued for $1 \mathrm{~h}$ at $40^{\circ} \mathrm{C}$. NP A66 was prepared by anionic EP with dextran $66.7 \mathrm{kDa}$. IBCA $(0.5 \mathrm{~mL})$ was added to a solution of dextran $(0.136 \mathrm{~g}$ in $10 \mathrm{~mL}$ $\mathrm{HNO}_{3} 0.2 \mathrm{~N}, 40^{\circ} \mathrm{C}$. The polymerization was pursued for $24 \mathrm{~h}$ at $40^{\circ} \mathrm{C}$. At the end the polymerization, dispersions were cooled in an ice bath and purified by dialysis against Milli- $Q^{\circledR}$ water using Spectra/Por membrane (MWCO 100,000 Da, Spectrum Laboratories, Irving, USA). Purified NP dispersions were stored at $4^{\circ} \mathrm{C}$ until use.

\subsubsection{Nanoparticle characterization}

Evaluation of the size and surface charge: Hydrodynamic diameter $\left(D_{H}\right)$ of nanoparticles was measured at $20^{\circ} \mathrm{C}$ by dynamic light scattering (DLS). Surface charge was assessed evaluating the zeta potential from measurements of the electrophoretic mobility by electrophoresis light scattering (ELS), using Smoluchowski's model. Measurements were carried out using a ZetaSizer Nano ZS90 (Malvern Instruments, Orsay, France). 
Determination of the mass concentration: Mass concentration of NP in dispersions $\left(\mathrm{M}_{\mathrm{c}}\right.$ in $\left.\mathrm{mg} \cdot \mathrm{mL}^{-1}\right)$ was determined by a gravimetric method. Known volume of the dispersion $(300 \mu \mathrm{L})$ was freeze-dried with a Christ Alpha 1-2 LDplus (Bioblock Scientific, Illkirch, France) for 24h. The dried weight was used to determine the $\mathrm{Mc}_{\mathrm{c}}$.

Calculation of the NP surface area concentration: The surface concentration $\left(\mathrm{S}_{\mathrm{c}}\right.$ in $\left.\mathrm{cm}^{2} \cdot \mathrm{mL}^{-1}\right)$ developed by the NP per $\mathrm{mL}$ of dispersion was calculated from Eq. 1 [19], using the mass concentration ( $M_{\mathrm{C}}$ in $\mathrm{mg} \cdot \mathrm{mL}^{-1}$ ), the $D_{H}$ (in $\mathrm{cm}$ ), and the density of tested nanoparticles ( $\mathrm{d}$ in $\mathrm{mg} \cdot \mathrm{cm}^{-3}$ ), which was previously reported by Vauthier et al. [20].

$S C=\frac{6 * M C}{d * D H}$

\subsection{Preparation of samples to be analyzed by C-IE and MultiCrossed-IE}

Human serum $(25 \mu \mathrm{L})$ was incubated with a given surface of nanoparticles $(50 \mu \mathrm{L})$ dispersed in Veronal Buffer Saline (VBS) $(25 \mu \mathrm{L})$. The VBS contained $0.15 \mathrm{mM} \mathrm{Ca}^{2+}$ and $0.5 \mathrm{mM} \mathrm{Mg}^{2+}$ ions and was prepared as described by Kazatchkine et al. [21]. Samples were incubated for $1 \mathrm{~h}$ at $37^{\circ} \mathrm{C}$. Then, they were immediately cooled to $4^{\circ} \mathrm{C}$ in an ice bath. For the robustness and precision study, EDTA and NM were added in order to stop proteolytic reactions occurring in the process of complement system activation [22] ( $4.13 \mu \mathrm{L}$ of EDTA disodium salt $0.5 \mathrm{M}$ and $2.16 \mu \mathrm{L}$ of NM at $10 \mathrm{mg}^{\mathrm{mL}} \mathrm{mL}^{-1}$ ). Samples were then either immediately analyzed by C-IE or stored at $-20^{\circ} \mathrm{C}$ until use within the few next days. The surface of NP exposed in the sample ( $\mathrm{s}_{\text {sample }}$ in $\left.\mathrm{cm}^{2} \cdot \mathrm{mL}^{-1}\right)$, can be calculated using Equation 2, with the volume of NP dispersion ( $v$ in $\mathrm{mL}$ ) in the total volume of incubation (Vtot in $\mathrm{mL}$ ).

Ssample $=\frac{S c * v}{V t o t}$

\subsection{Crossed Immunoelectrophoresis}

\subsubsection{C-IE classical method}

The C-IE method was detailed by Walker [23], then applied to C3 protein by Passirani et al. [11]. Samples were prepared as described in 2.3. Then, $5 \mu \mathrm{L}$ of each sample were filled into wells formed on a $1 \%$ agarose gel plate $(13 \times 10 \mathrm{~cm})$ for the first dimension of electrophoresis. After $1 \mathrm{~h} 15 \mathrm{~min}$ of separation, bands corresponding to each sample were cut and disposed on Gel-Fix ${ }^{\text {TM }}$ films $(5 \times 7 \mathrm{~cm}$ each). Agarose gel $1 \%$ containing the antibody was then casted on the remaining free area of the film for the second dimension electrophoresis that lasted for $18 \mathrm{~h}$ using a Multiphor II electrophoresis system (GE Healthcare, Velizy-Villacoublay, France). Five samples were run at the same time on five different gel slabs $(5 \times 7 \mathrm{~cm})$. 


\subsubsection{New serial multiple crossed IE at a micro scale (MultiCrossed-IE)}

\subsubsection{Evaluation of the heat resistance of the antibody}

The heat resistance of the antibody was assessed by radial immunodiffusion [24]. A gel plate was prepared on a Gel-Fix ${ }^{\mathrm{TM}}$ film with a solution of agarose $0.7 \%$ containing human serum $\left(0.17 \mu \mathrm{L} / \mathrm{cm}^{2}\right.$ of gel), in Tricine buffer (Calcium Lactate $1 \mathrm{mM}$, TRIS $63 \mathrm{mM}$, Tricine $27 \mathrm{mM}$, in MilliQ ${ }^{\circledR}$ water, pH 8.6). Wells were formed in the agarose gel to receive $4 \mu \mathrm{L}$ of pre-heated $(20,50,55,60,65,70,75,80$ and $90^{\circ} \mathrm{C}$ ) antibody solutions (1.4 mg. $\mathrm{mL}^{-1}$ in PBS) for 4 minutes. The gels were placed in a humid chamber for 24h prior drying and staining with Coomassie blue [25]. The diameter of the precipitated rings was measured to calculate the areas of circles. The latter were plotted against the corresponding temperature at which the antibody was heated.

\subsubsection{Preparation of the gel for MultiCrossed-IE}

Agarose gel $1 \%$ ( $40 \mathrm{~mL}$ ) was prepared in Tricine buffer. When the temperature of the gel reached $60^{\circ} \mathrm{C}, 1.17 \mathrm{~mL}$ of anti-C3 antibody at $1 \mathrm{mg} \cdot \mathrm{mL}^{-1}$ in PBS was added. After rapid homogenization, the solution was spread on a $15 \times 20 \mathrm{~cm}$ Gel-Fix ${ }^{\mathrm{TM}}$ film (Fig. 1A).

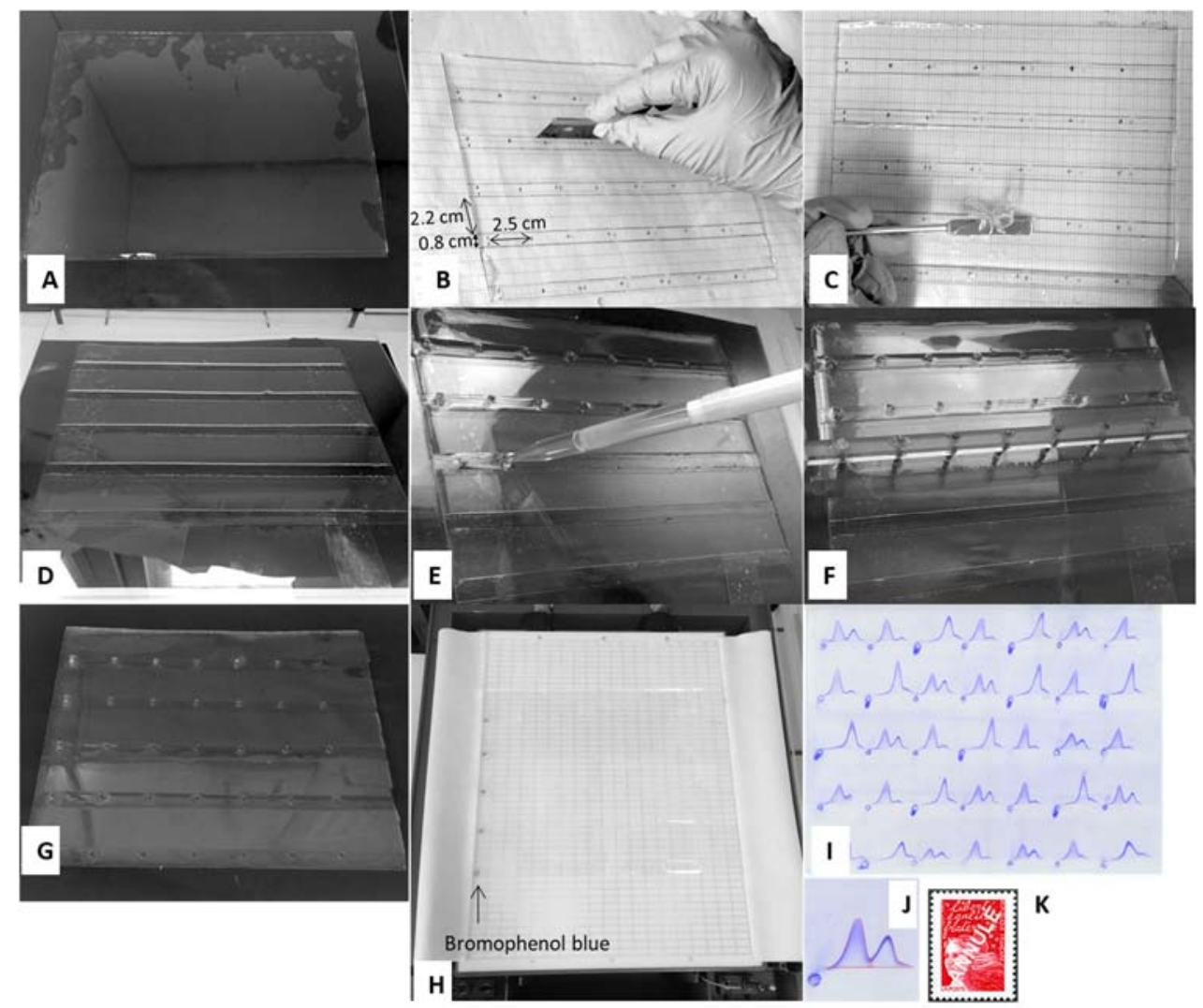

Figure 1: Preparation of the gel plates for MultiCrossed-IE. A) Agarose gel slab containing anti-C3 antibody. B) Cutting of gel bands following a template. C) Removing pre-cut bands with a spatula. D) Gel with cut bands. E) Agarose gel filling of the bands. F) Application of the comb for wells formation. G) Final gel ready for sample loading. H) Gel loaded with samples and indicator for first dimension migration. I) Numerized gel after 2D migration, staining and drying. J) Example of integration of electrophoregram peaks. K) Comparison with a stamp at the same size scale ( CLa Poste, 2001, Eve Luquet). 
After solidification, five $8 \mathrm{~mm}$ bands were removed as illustrated in Figure 1B, C,D. Each gap was then filled with $1.8 \mathrm{~mL}$ of a $1 \%$ agarose gel prepared in Tricine buffer (Fig. 1E). Wells were formed at the same time using a homemade comb (Fig. 1F). A distance of $2.5 \mathrm{~cm}$ was left between wells, allowing seven samples to be run in series in a band of $20 \mathrm{~cm}$ long (i.e. 35 samples to be run in a $15 \times 20 \mathrm{~cm}$ gel, Fig. 1G). A second well on the left side of each band was made under the sample well, in order to run Bromophenol blue as an indicator of migration for the first dimension of the electrophoresis.

\subsubsection{Electrophoresis runs}

The tricine buffer was used as electrophoresis buffer. The gel was placed in Multiphor II electrophoresis system (GE Healthcare, Velizy-Villacoublay, France) and wells were filled with $2.5 \mu \mathrm{L}$ of samples for the serial migration. Bromophenol blue $\left(1.3 \mathrm{mg} \cdot \mathrm{mL}^{-1}, 2.5 \mu \mathrm{L}\right)$ was placed in the secondary wells on the left (Fig. $1 \mathrm{H})$. Samples were then subjected to the first dimension electrophoresis $(600 \mathrm{~V}, 16 \mathrm{~mA}, 100 \mathrm{~W})$, freely migrating in the agarose gel band according to their molecular weight and charge. Electrophoresis was stopped when the blue indicators have crossed 6 $\mathrm{cm}$. Then, the gel was turned by $90^{\circ}$ to achieve the second dimension corresponding to the rocket immunoelectrophoresis ( $500 \mathrm{~V}, 12 \mathrm{~mA}, 100 \mathrm{~W}$ ), that lasted for 3h30min. Gels were dried and stained as described previously [25].

\subsubsection{Scanning and quantification}

The gels were scanned at a resolution of $800 \mathrm{dpi}$ (Scanner Epson Perfection V100 Photo) (Fig. 11). Area under peaks was integrated using ImageJ software (Fig. 1J). The first peak on the left side was recognized as native $\mathrm{C} 3$, whereas the second peak from the left was attributed to protein fragments derived from C3 cleavage. The \% of activation was expressed as the ratio of peak area of cleaved protein regarding the total peak area of $\mathrm{C} 3$ native and fragments.

\subsection{Robustness and precision of the method}

\subsubsection{Sample preparation}

Three samples with different degrees of activation of the C3 protein were prepared from dispersions R66, R17 and A66 used at a surface concentration of 1934, 1874 and $3934 \mathrm{~cm}^{2} \cdot \mathrm{mL}^{-1}$ respectively. These samples appropriately corresponded to low (A0), partial (A50) and full activation (A100) of the protein C3 and were prepared as mentioned in section 2.3.

\subsubsection{Exploration of robustness and precision of the method}

Several factors were tested in order to investigate the robustness and precision of the method, as described by ICH [26] and ISO standard [27]. The robustness of a method reflects its capacity to give unaffected results under small variation of the measurement conditions and thus give indications about its reliability for a normal usage $[26,27]$.

Factors considered in the robustness study were: 
- The position of the sample on the slab gel. Two different gels containing the same samples disposed at different positions were run on the same day on the same electrophoresis tank.

- The electrophoresis system. Two different gels with samples at the same position in both gels were simultaneously run on two distinct electrophoresis systems.

- The influence of the analyst. Two different experimenters did the same experiment, using the same samples on the same system. Each experimenter prepared its own gel, ran the electrophoresis independently and analyzed the obtained gel after coloration.

- The sample preparation. A total of five preparations of each sample (A0, A50 or A100) were realized the same day. Each sample was analyzed on one gel slab.

The precision of a method expresses the closeness between a series of measurements under defined conditions $[26,27]$. The precision was investigated through intra-day variation (repeatability) and inter-day variation (intermediate precision).

Three models of NP samples [14, 28] were repeated and analyzed for their ability to give the same activation under variations of the above mentioned experimental factors as summarized in Table 1 . It is noteworthy that the gel preparation was independent for each experiment.

Table 1: Evaluation of robustness and precision of the MultiCrossed-IE monitoring the activation of the protein $\mathrm{C} 3$ by three samples of nanoparticles showing low activation (AO), medium activation (A50) and high activation (A100) of the protein C3. A: General design of ANOVA tests used for factors influence of the position of the sample (Position), electrophoresis system (System), analyst (Analyst), sample preparation (Sample prep) and day (Intra-day and Inter-day). i and ii represent the number of levels of the tested factor and the number of replicates made for a given sample in each gel respectively. B: Results of the statistical analysis by ANOVA tests. Robustness was evaluated by $p$ values (The factor did not introduce a significant difference for a $p$-value $>0.05$, see paragraph 2.5.3.). Precision was assessed by RSD values.

A

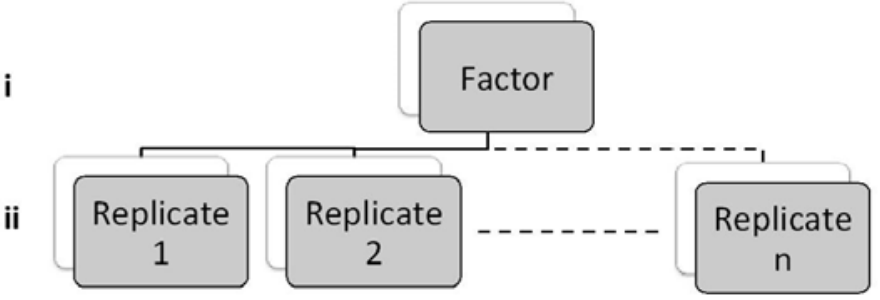

B

\begin{tabular}{|c|c|c|c|c|c|c|c|}
\hline & & \multicolumn{2}{|r|}{ AO } & \multicolumn{2}{|c|}{ A50 } & \multicolumn{2}{|c|}{ A100 } \\
\hline Robustness & i & ii & p-value & ii & p-value & ii & p-value \\
\hline Position & 2 & 8 & 0.461 & 10 & 0.772 & 11 & 0.926 \\
\hline System & 2 & 9 & 0.296 & 9 & 0.461 & 11 & 0.711 \\
\hline Analyst & 2 & 9 & 0.135 & 9 & 0.312 & 7 & 0.146 \\
\hline $\begin{array}{c}\text { Sample } \\
\text { prep }\end{array}$ & 5 & 6 & 0.433 & 6 & 0.786 & 5 & 0.325 \\
\hline Precision & $\begin{array}{l}i \\
3\end{array}$ & $\begin{array}{l}\text { ii } \\
7\end{array}$ & RSD & $\begin{array}{l}\text { ii } \\
8\end{array}$ & RSD & $\begin{array}{l}\text { ii } \\
8\end{array}$ & RSD \\
\hline Intra-day & & & 19.3 & & 6.5 & & 2.2 \\
\hline Inter-day & & & 3.4 & & 3.2 & & 0.9 \\
\hline
\end{tabular}




\subsubsection{Statistical analysis of the MultiCrossed-IE}

The investigation of the robustness and precision of the method was performed by means of ANOVA tests, as described in the GUM [29] and the standard ISO [30]. The General Linear Model of ANOVA test in Minitab 16.0 was used on this purpose. Briefly, ANOVA test allows determining whether one or several factors have a significant influence on the response of the measured variable, here the $\%$ activation of the protein C3. ANOVA was applied after verification of the hypotheses allowing its applicability, namely the normal distribution of residuals (Ryan-Joiner's test) and variances homoscedasticity (Levene's model).

The robustness was assessed through the factors position, system, analyst and sample preparation by means of the $p$-value. The $p$-value corresponds to the probability to find the observed, or more extreme, results when the null hypothesis is true i.e. the studied factor has no significant effect on the variable response. If the $p$-value is higher than the significance level fixed at 0.05 in this work, it suggests that the data are consistent with the assumption that the null hypothesis is true and the null hypothesis has to be accepted. So, the tested factor did not introduce significant difference on the response variable when $p$-value resulting from its associated ANOVA was higher than 0.05 . The threshold for the $p$-value was chosen consistently with those generally found in the literature. To study the precision of the method, we assessed the intermediate precision and the repeatability via the calculation of the RSD of \% C3 activation values determined for A0, A50 and A100.

\subsection{Characterization of C3 activation induced by nanoparticles}

Samples of the three types of NP were prepared with different amounts of surface area (ranging from 500 to $4950 \mathrm{~cm}^{2} \cdot \mathrm{mL}^{-1}$ ) and analyzed by MultiCrossed-IE. The \% of activation of protein C3 was determined and plotted against the concentration of NPs expressed in surface area $\left(\mathrm{cm}^{2} \cdot \mathrm{mL}^{-1}\right)$. The concentration in NPs producing $50 \%$ of the cleavage of the protein $C 3$ was defined as the $\mathrm{C}_{3} \mathrm{~A}_{50}$.

\section{Results}

\subsection{Nanoparticle characterization}

Hydrodynamic diameter, Polydispersity index (PDI), zeta potential, mass and surface concentration of NP in dispersions are summarized in Table 2 and were consistent with those found in previous works $[14,28,31]$.

\subsection{Heat resistance of the antibody}

To prepare agarose gel plates for the MultiCrossed-IE, the agarose gel must be spread on a $15 \times 20 \mathrm{~cm}$ Gel-Fix ${ }^{\mathrm{TM}}$ film. During this operation, the antibody is added to a hot agarose solution and must resist to the high temperature required to cast a homogeneous gel plate. A preliminary experiment aimed to determine the maximum temperature at which full activity of the antibody was preserved. This 
was assessed by a radial immunodiffusion method designed on this purpose. As shown in Figure S1, decrease of the immunodiffusion circle areas was clearly observed for anti-C3 antibody samples heated above $60^{\circ} \mathrm{C}$ that can be explained by the denaturation of the antibody. The full activity of the antibody was preserved after heating at $60^{\circ} \mathrm{C}$ which was the maximum temperature that can be used to prepare gel plates. Gels for the MultiCrossed-IE were then casted at $60^{\circ} \mathrm{C}$.

Table 2: Characteristics of the three dispersions of model NPs used in the study and values of $C_{3} A_{50}$ determined by MultiCrossed-IE.

\begin{tabular}{|c|c|c|c|c|c|c|}
\hline NP & $D_{H}(n m)^{*}$ & PDI $^{*}$ & $\begin{array}{l}\text { Zeta potential } \\
\quad \neq *(\mathrm{mV})\end{array}$ & $\begin{array}{c}\mathrm{M}_{\mathrm{c}}^{* * *} \\
\left(\mathrm{mg} \cdot \mathrm{mL}^{-1}\right)\end{array}$ & $\begin{array}{c}\mathrm{S}_{\mathrm{c}} \\
\left(\mathrm{cm}^{2} \cdot \mathrm{mL}^{-1}\right)\end{array}$ & $\begin{array}{l}\mathrm{C}_{3} \mathrm{~A}_{50} * * * * \\
\left(\mathrm{~cm}^{2} \cdot \mathrm{mL}^{-1}\right)\end{array}$ \\
\hline $\mathrm{R} 17$ & 193 & 0,03 & -11.7 & 49.1 & $13.4 \cdot 10^{3}$ & 1625 \\
\hline A66 & 88 & 0,1 & $-5,6$ & 36.9 & $22.1110^{3}$ & 1500 \\
\hline R66 & 281 & 0,04 & -5.2 & 52.8 & $9.9 \cdot 10^{3}$ & $>4900$ \\
\hline
\end{tabular}

\subsection{MultiCrossed-IE (versus orginal method)}

The gel plate was conceived to achieve the migration of 7 samples on the same horizontal line. 5 bands were built in the gel for a parallel migration of samples. Compared with the original method [11] allowing 5 samples to be analyzed at once on individual $5 \times 7 \mathrm{~cm}$ gel plates, the designed serial electrophoresis provided 35 stamp-sized electrophoregrams $(2.8 \times 3 \mathrm{~cm})$. It was checked that performances of the original method were preserved in the stamp-size electrophoregrams obtained from the MultiCrossed-IE (Table 3 and Fig. S2).

\subsection{Study of the robustness and precision of the method}

For the evaluation of robustness and precision, samples A0, A50 and A100 were prepared with inhibitors of complement cascade added at the end of the incubation. Same samples could be analyzed several times to investigate the robustness and precision of the MultiCrossed-IE using statistical analysis by ANOVA. Different factors were independently assessed. Hypotheses verifications for the ANOVA analysis are shown in S3. The obtained p-values and RSDs for the different tested factors are depicted in Table 1. Results showed that there was no significant bias introduced by the position of a sample on the gel plate, the electrophoresis system, the analyst doing the experiment and the preparation of the sample. It is noteworthy that no significant difference was found even when two different analysts applied the experiment. This means that the results were not significantly different analyzing the 3 different samples (A0, A50 and A100) while the method was performed on gels made by the two independent analysts and the analyses of the electrophoregrams were carried out independently by the two analysts. Robustness was verified for a confidence level of $95 \%$ performing MultiCrossed-IE on identical samples. For the precision, RSDs of 
intra-day variation reflecting the repeatability and RSDs of inter-day variation corresponding to intermediate precision were summarized in the lower part of Table 1B. The RSD values found for the inter-day were below $4 \%$ for all samples (A0, $A 50$ and $A 100)$. This indicated that there was no variation added by the day of the experiment. The repeatability remains constant from one day to another. The $p$-value associated to inter-day variation was also determined giving $p$-values of 0.814 , 0.169 and 0.300 for $\mathrm{A} 0, \mathrm{~A} 50$ and $\mathrm{A} 100$ respectively. As all these values were superior to 0.05 showing that no significant variation was introduced by the factor day (see paragraph 2.5.3).

Table 3: Comparison of the main features between the original method and MultiCrossed-IE.

Original method

\begin{tabular}{|ccc|}
\hline Electrophoresis Duration & $19 \mathrm{~h} 15 \mathrm{~min}$ & $4 \mathrm{~h} 45 \mathrm{~min}$ \\
\hline Number of analyzes & 5 & 35 \\
\hline Quantity of Ab/analysis & $130 \mu \mathrm{g}$ & $34 \mu \mathrm{g}$ \\
\hline Volume of Gel/analysis & $6.6 \mathrm{~mL}$ & $1.4 \mathrm{~mL}$ \\
\hline $\begin{array}{c}\text { Gel-Fix }{ }^{\mathrm{TM}} \text { surface/analysis } \\
\text { Sample consumption/ } \\
\text { analysis }\end{array}$ & $35 \mathrm{~cm}^{2}$ & $8.4 \mathrm{~cm}^{2}$ \\
\hline Gel plate cost/analysis & $5 \mu \mathrm{L}$ & $2.5 \mu \mathrm{L}$ \\
\hline
\end{tabular}

Electrophoregrams of A50 at a same size scale* - Comparison with a the size of a stamp (@La Poste, 2001, Eve Luquet )

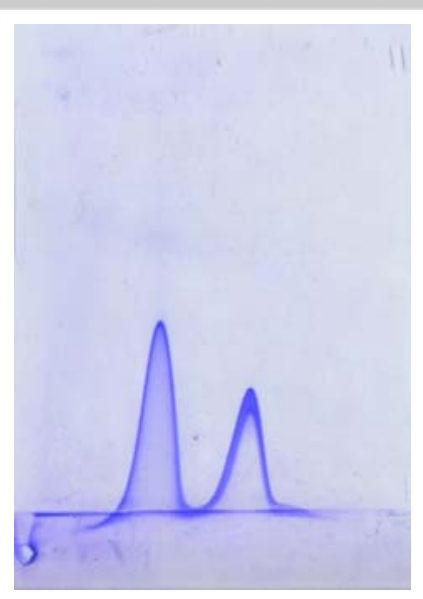

*See more in Fig. S2

\subsection{Complement $\mathrm{C} 3$ activation triggered by nanoparticles}

The interaction of nanomaterials with blood proteins is a matter of contact between these two entities and is thus driven by the amount of surface engaged in this process. Hence, the surface of NP exposed to serum proteins impacts on the strength of interaction triggered and this phenomenon 
can be exploited to define a characteristic of a given nanomaterial toward its ability to activate the complement cascade. Protein C3 activation patterns were studied for the three nanoparticles used as reference samples providing with different levels of activation. Investigating the \% of cleaved C3 fragments produced by different amounts of NP's incubated in serum, the surface of NP that activates $50 \%$ of protein $C 3$ present in the sample was determined $\left(C_{3} A_{50}\right)$. NPs R17 and $A 66$ have reached full activation with the highest tested concentrations. The curve giving the $\%$ activation as a function of the concentration showed a sigmoidal shape (Fig. 2).
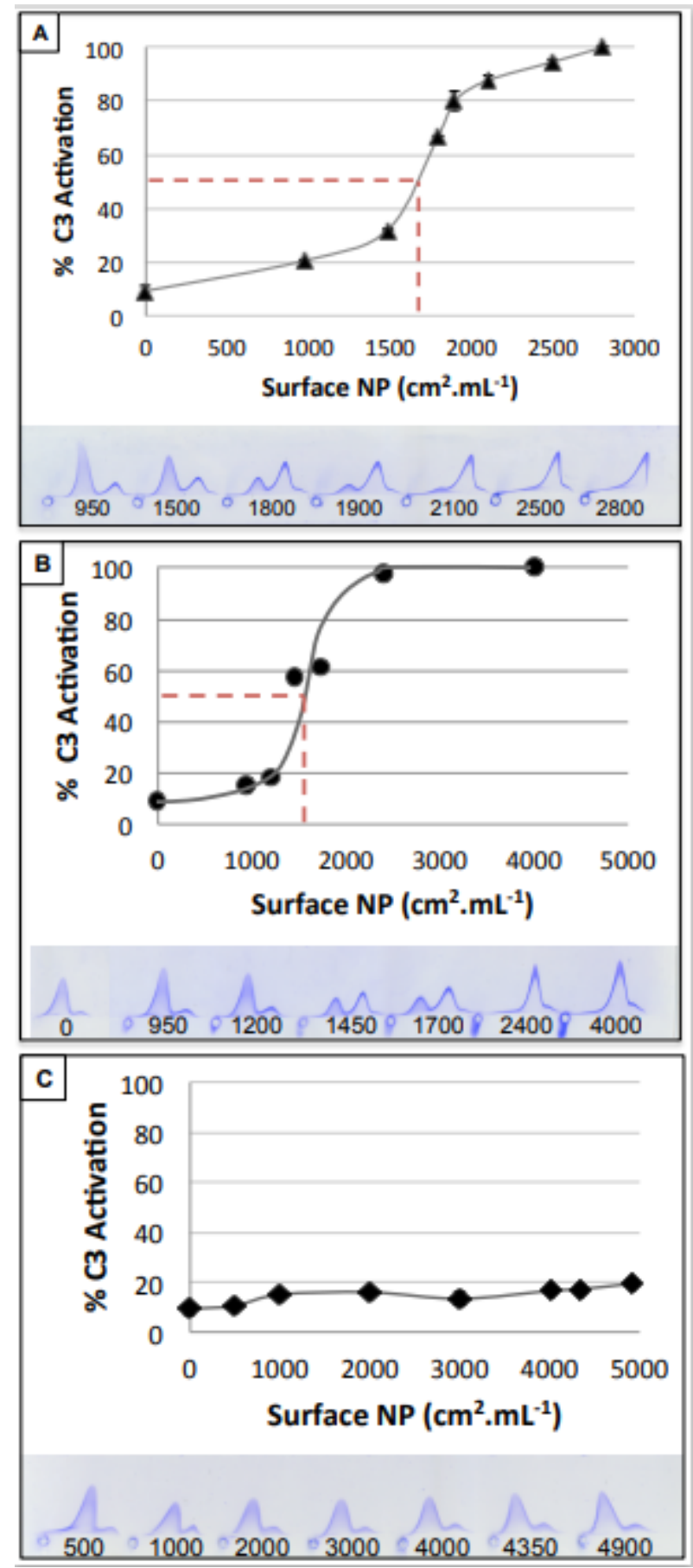

Figure 2: Determination of $C_{3} A_{50}$ for the three model NPs R17 (A), A66 (B) and R66 (C). Top Graph representing the values of $\mathrm{C} 3 \%$ activation obtained in function of NP concentration for R17, A66 and R66 respectively. Bottom - Electrophoregrams obtained by MultiCrossed-IE with increasing concentration in NP added in the sample test. Values correspond to tested surface of NP in $\mathrm{cm}^{2} . \mathrm{mL}^{-1}$. 
The $\mathrm{C}_{3} \mathrm{~A}_{50}$ that could be determined were $1625 \mathrm{~cm}^{2} \cdot \mathrm{mL}^{-1}\left(6.0 \mathrm{mg} \cdot \mathrm{mL}^{-1}\right)$ for $\mathrm{R} 17$ and $1500 \mathrm{~cm}^{2} \cdot \mathrm{mL}^{-1}(2.5$ $\mathrm{mg} \cdot \mathrm{mL}^{-1}$ ) for $\mathrm{A66}$ (Table 2). The results were consistent with data of the literature reporting a high \% of activation of these two types of NP at a tested surface of $2000 \mathrm{~cm}^{2} \cdot \mathrm{mL}^{-1}[14,28]$. Nanoparticle R66 does not activate the complement above $20 \%$ up to a surface concentration of $4950 \mathrm{~cm}^{2} \cdot \mathrm{mL}^{-1}(26.4$ mg. $\mathrm{mL}^{-1}$ ) (Fig. 4C). The activation observed was just above the level of the spontaneous activation of C3 observed in the experimental conditions used in this study ( $9 \%$ of activation). These results were also consistent with previous data provided at a surface of $2000 \mathrm{~cm}^{2} \cdot \mathrm{mL}^{-1}$ [28]. The very low capacity of these NP to activate the complement system revealed here is consistent with their stealth properties reported in vivo [32] and the property of their dextran corona to hamper interactions of the NP core with protein C3 [33].

\section{Discussion}

C-IE is a quite old method [34], which was used in several immunological applications [35]. The originality of the proposed method includes the possibility to migrate samples in series during the first and second dimensions. Traditional methods used to make several migrations in parallel during the first dimension, before cutting bands of the $1^{\text {st }}$ dimension gel to transpose on the second dimension gel containing the antibody for the IE $[11,35]$. The method proposed in this work greatly simplifies the complex handling found in previous methods while it did not affect the performance. With the new method, one single gel is prepared and the only manipulation between the first and the second electrophoresis is to turn the gel by $90^{\circ}$. The overall time required to perform the $2 \mathrm{D}$ electrophoresis runs was also considerably reduced (4h45min against $19 \mathrm{~h} 15 \mathrm{~min}$ with the previous method). Simultaneously, the number of analysis performed in one run was multiplied by 7 . Because the size of gel for one sample was reduced to the size of a stamp (from $5 \times 7 \mathrm{~cm}$ to $2.8 \times 3 \mathrm{~cm}$ ), a significant reduction of the amount of reagents was also achieved (Gel-Fix ${ }^{\mathrm{TM}}$, gel, antibody, sample), hence reducing the cost for one analysis. The different improvements are summarized in Table 3.

ANOVA is commonly used in validation of chromatographic methods [36, 37]. In the present study, it was applied to validate an electrophoretic method. To carry on this validation, we have performed experiments with a large number of gels. The results have demonstrated that the method is remarkably robust varying different factors. Indeed, the robustness study of the developed MultiCrossed-IE showed that position, electrophoresis system, analyst and preparation of the sample did not have a significant influence on the results of C3 activation. RSDs for intra and inter-day variations conformed with values found in the literature. Level of complement C3 activation is a complex process that is not fixed and evolves with time. For this study, standards did not exist, it was thus necessary to halt the evolution of $\mathrm{C} 3$ activation after the time of incubation, in order to use a sample several times for the validation purpose. Further activation was blocked by addition of EDTA and NM. We could then store and re-use the same sample for validation of the tested factor.

The proposed method of the MultiCrossed-IE was applied to determine the pattern of activation of C3 triggered by the three model NPs used in the present work. NP concentration was expressed by 
means of the exposed surface. Indeed, NPs have different size while protein adsorption depends on the available area on nanoparticle surface. Contact of proteins with NP surface are responsible for the activation of the complement cascade and it appeared logical to express the quantity of nanoparticles by the surface exposed reported to the volume of sample.

Thanks to the high throughput capacity given by the new MultiCrossed-IE method, it was applied to screen the influence of the amount of surface of NP tested on the level of complement C3 activation. A new parameter was defined as the surface concentration that induces $50 \%$ of protein C3 cleavage after $1 \mathrm{~h}$ of incubation with serum at $37^{\circ} \mathrm{C}\left(\mathrm{C}_{3} \mathrm{~A}_{50}\right)$. The values determined for the three types of NP may be of interest to class them and could eventually help to anticipate their accumulation in the immune system after intravenous administration or their capacity to induce a CARPA reaction. The new MultiCrossed-IE now provides with the opportunity to determine this characteristic from a validated method of evaluation of complement C3 protein activation. This is in contrast with many other methods that only allow comparisons at a single tested concentration and are eventually based on an indirect evaluation of $\mathrm{C} 3$ activation such as the $\mathrm{CH} 50$.

New modalities of the application of C-IE were established allowing high throughput and making easier the handling by performing MultiCrossed-IE on a single gel plate. Demonstration of the robustness of the proposed protocol towards different factors and improvements of the method should renew the interest of C-IE methods for the analysis of specific proteins. A straightforward application is the evaluation of the activation of protein $\mathrm{C} 3$ of the complement system triggered by nanomaterials. It allows the evaluation of nanomaterial interactions with the immune system, which are important to anticipate their safety and biodistribution.

This work was financially supported by BPI France - Project NICE.

The authors declare no conflict of interest.

\section{References}

[1] Zolnik, B. S., González-Fernández, Á., Sadrieh, N., Dobrovolskaia, M. A., Endocrinology 2010, 151, 458-465.

[2] Boraschi, D., Duschl, A., Nanoparticles and the immune system: safety and effects, Academic Press, Oxford 2013.

[3] Dobrovolskaia, M. A., Aggarwal, P., Hall, J. B., McNeil, S. E., Mol. Pharm. 2008, 5, 487-495.

[4] Moghimi, S. M., Andersen, A. J., Ahmadvand, D., Wibroe, P. P., Andresen, T. L., Hunter, A. C., Adv. Drug Deliv. Rev. 2011, 63, 1000-1007.

[5] Szebeni, J., Toxicology 2005, 216, 106-121.

[6] Szebeni, J., Mol. Immunol. 2014, 61, 163-173.

[7] Harboe, M., Thorgersen, E. B., Mollnes, T. E., Adv. Drug Deliv. Rev. 2011, 63, 976-987.

[8] Salvador-Morales, C., Sim, R. B., in: Dobrovolskaia, M. A., McNeil, S.E. (Eds), Handbook of immunological properties of engineered nanomaterials, World Scientific, Singapore 2013, pp. 357384.

[9] Mollnes, T. E., Jokiranta, T. S., Truedsson, L., Nilsson, B., Rodriguez de Cordoba, S., Kirschfink, M., 
Mol. Immunol. 2007, 44, 3838-3849.

[10] Neun, B. W., Ilinskaya, A., Dobrovolskaia, M. A., Analysis of Complement Activation by EIA, NCL Method ITA-5.2 Version 1.2, 2015. http://ncl.cancer.gov/NCL_Method_ITA-5.2.pdf (consulted on October 2015).

[11] Passirani, C., Barratt, G., Devissaguet, J.-P., Labarre, D., Life Sci. 1998, 62, 775-785.

[12] Mosqueira, V. C. F., Legrand, P., Gulik, A., Bourdon, O., Gref, R., Labarre, D., Barratt, G., Biomaterials 2001, 22, 2967-2979.

[13] Vonarbourg, A., Passirani, C., Saulnier, P., Simard, P., Leroux, J. C., Benoit, J. P., J Biomed Mater $\operatorname{Res} A$ 2006, 78A, 620-628.

[14] Bertholon, I., Vauthier, C., Labarre, D., Pharm. Res. 2006, 23, 1313-1323.

[15] Nilsson, B., Ekdahl, K. N., Mollnes, T. E., Lambris, J. D., Mol. Immunol. 2007, 44, 82-94.

[16] Leslie, M., Science 2012, 337, 1034-1037.

[17] Gros, P., Milder, F. J., Janssen, B. J. C., Nat. Rev. Immunol. 2008, 8, 48-58.

[18] Chauvierre, C., Labarre, D., Couvreur, P., Vauthier, C., Macromolecules 2003, 36, 6018-6027.

[19] Vittaz, M., Bazile, D., Spenlehauer, G., Verrecchia, T., Veillard, M., Puisieux, F., Labarre, D., Biomaterials 1996, 17, 1575-1581.

[20] Vauthier, C., Schmidt, C., Couvreur, P., J Nanopart Res 1999, 1, 411-418.

[21] Kazatchkine, M., Nydegger, U., Hauptmann, G., Techniques du complément, Éd. INSERM, 1985.

[22] Bergseth, G., Ludviksen, J. K., Kirschfink, M., Giclas, P. C., Nilsson, B., Mollnes, T. E., Mol. Immunol. 2013, 56, 232-239.

[23] Walker, J. M., in: Walker, J. M. (Ed.), The Protein Protocols Handbook, Springer, 1996, pp. 763768.

[24] Mancini, G., Carbonara, A.0., Heremans J.F., Immunochemistry 1965, 2, 235-254.

[25] Walker, J. M., in: Walker, J. M. (Ed.), The Protein Protocols Handbook, Springer, 1996, pp. 757762.

[26] ICH Harmonized Tripartite Guideline, Validation of analytical procedures: Text and Methodology Q2(R1), Current Step 4 version, Parent Guideline dated 27 October 1994, (Complementary Guideline on Methodology dated 6 November 1996 incorporated in November 2005).

http://www.ich.org/fileadmin/Public_Web_Site/ICH_Products/Guidelines/Quality/Q2_R1/Step4/Q2_ R1_Guideline.pdf (consulted on May 2016).

[27] ISO 5725-1:1994: Accuracy (trueness and precision) of measurement methods and results - Part 1: General principles and definitions.

[28] Labarre, D., Vauthier, C., Chauvierre, C., Petri, B., Muller, R., Chehimi, M., Biomaterials 2005, 26, 5075-5084.

[29] Guide to the expression of uncertainty in measurement, JCGM 100:2008 GUM 1995 with minor corrections. http://www.bipm.org/utils/common/documents/jcgm/JCGM_100_2008_E.pdf (consulted on May 2016).

[30] ISO 5725-3:1994: Accuracy (trueness and precision) of measurements methods and results - Part 3: Intermediate measures of the precision of a standard measurement method.

[31] Bertholon, I., Hommel, H., Labarre, D., Vauthier, C., Langmuir 2006, 22, 5485-5490.

[32] Alhareth, K., Vauthier, C., Bourasset, F., Gueutin, C., Ponchel, G., Moussa, F., Eur J Pharm Biopharm 2012, 81, 453-457.

[33] Vauthier, C., Persson, B., Lindner, P., Cabane, B., Biomaterials 2011, 32, 1646-1656.

[34] Laurell, C. B., Anal. Biochem. 1965, 10, 358-361.

[35] Grubb, A. O., Scand. J. Immunol. 1983, 17, 113-124.

[36] Vander Heyden, Y., De Braekeleer, K., Zhu, Y.,Roets, E., Hoogmartens, J., De Beer, J., Massart, D. L., J. Pharmaceut. and Biomed. 1999, 20, 875-887.

[37] Careri, M., Elviri, L., Mangia, A., J. AOAC Int. 2001, 84, 1383-1392. 


\section{Supporting information}

Serial multiple crossed immunoelectrophoresis at a micro scale: a stamp-size 2D immunoanalysis of protein C3 activation caused by nanoparticles

Jean-Baptiste Coty, Fanny Varenne, Jean-Jacques Vachon, Christine Vauthier*

Institut Galien Paris-Sud, CNRS, Univ. Paris-Sud, Université Paris-Saclay, 5 rue Jean-Baptiste Clément, 92290 Châtenay-Malabry, France

*Correspondence: Dr. Christine Vauthier, CNRS UMR 8612, Institut Galien Paris Sud, Univ. Paris-Sud, Université Paris-Saclay, 5, rue Jean-Baptiste Clément, 92296 Châtenay-Malabry, France. Fax: +33 146835946. E-mail: christine.vauthier@u-psud.fr 


\section{S1: Heat resistance of the antibody}

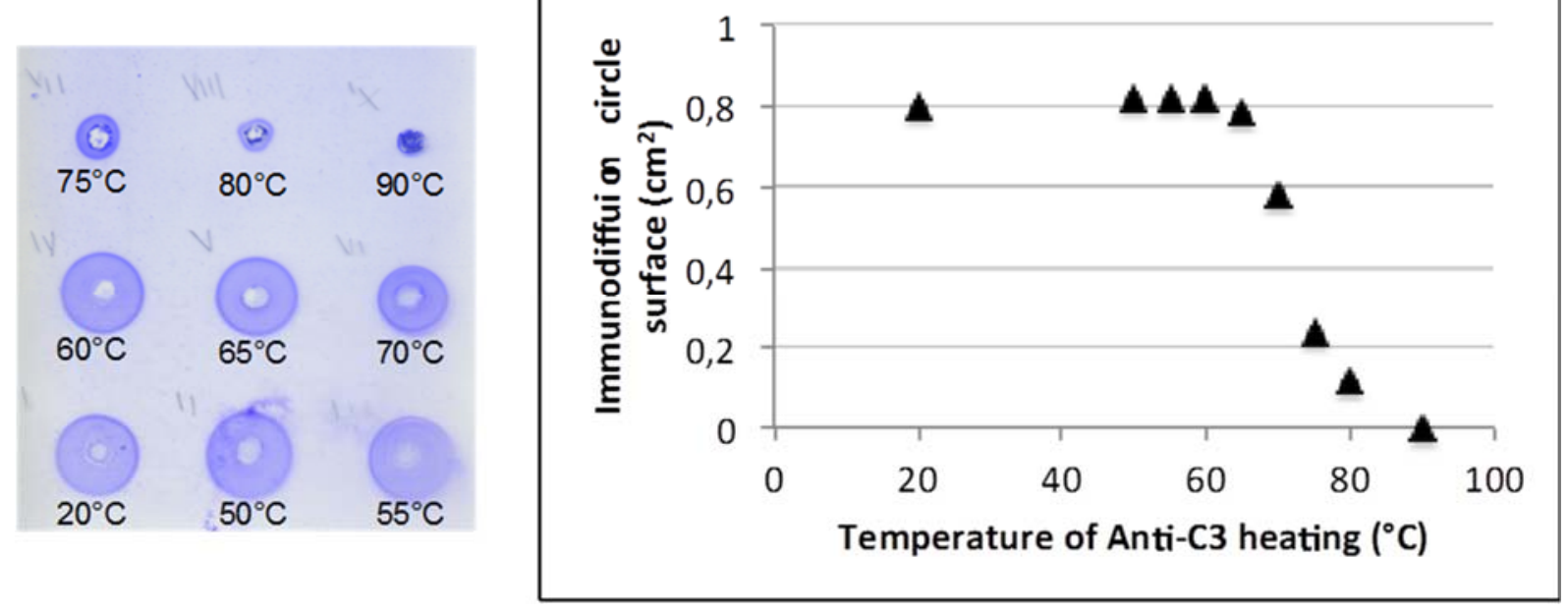

Figure S1: (A) Immunoprecipitated rings obtained after 24h of radial immunodiffusion for indicated heating of antibodies. (B) Plot of immunoprecipitated circles areas against temperature of antibody heating. 


\section{S2: Comparison between classical IE and MuliCrossed-IE}

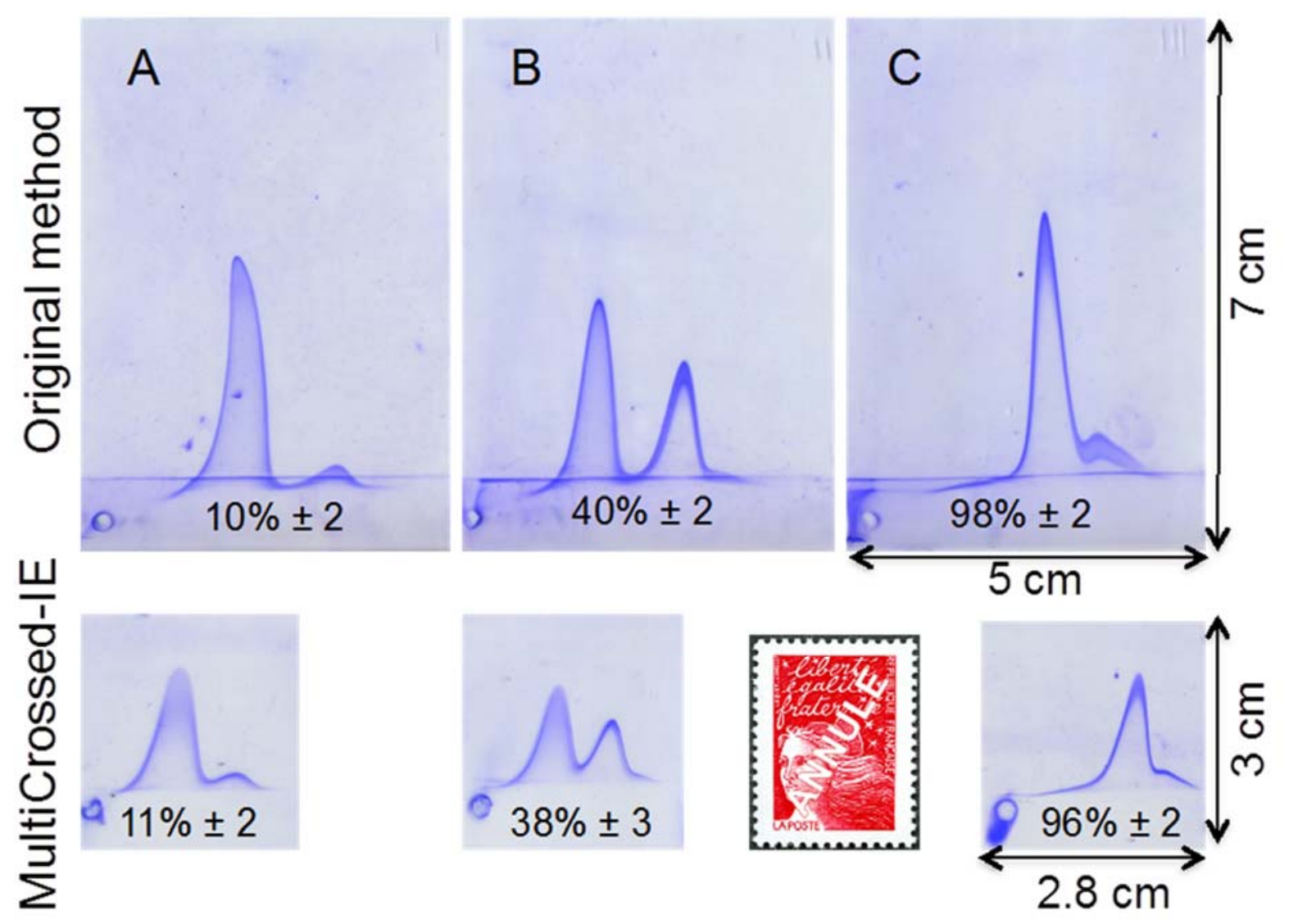

Figure S2: Comparison of the original size immunoelectrophoregrams (raw on the top) with the stamp-size obtained from the MultiCrossed-IE (raw on the bottom). A stamp ( $C$ La Poste, 2001, Eve Luquet) is shown for size comparison with stamp-size electrophoregram. $-A, B$ and $C$ correspond to $A 0, A 50$ and $A 100$ respectively. Percentages correspond to the \% of $C 3$ activation. 


\section{S3: Verification of ANOVA's hypotheses: Normal distribution of} residues (Ryan-Joiner's test) and Variance's homoscedasticity (Levene's test)

S3-A: Distribution of residues and Ryan-Joiner's Test results for robustness study of tested factors: Position (a), System (b), Analyst (c), Sample preparation (d) and Day (e).

(a) Position factor
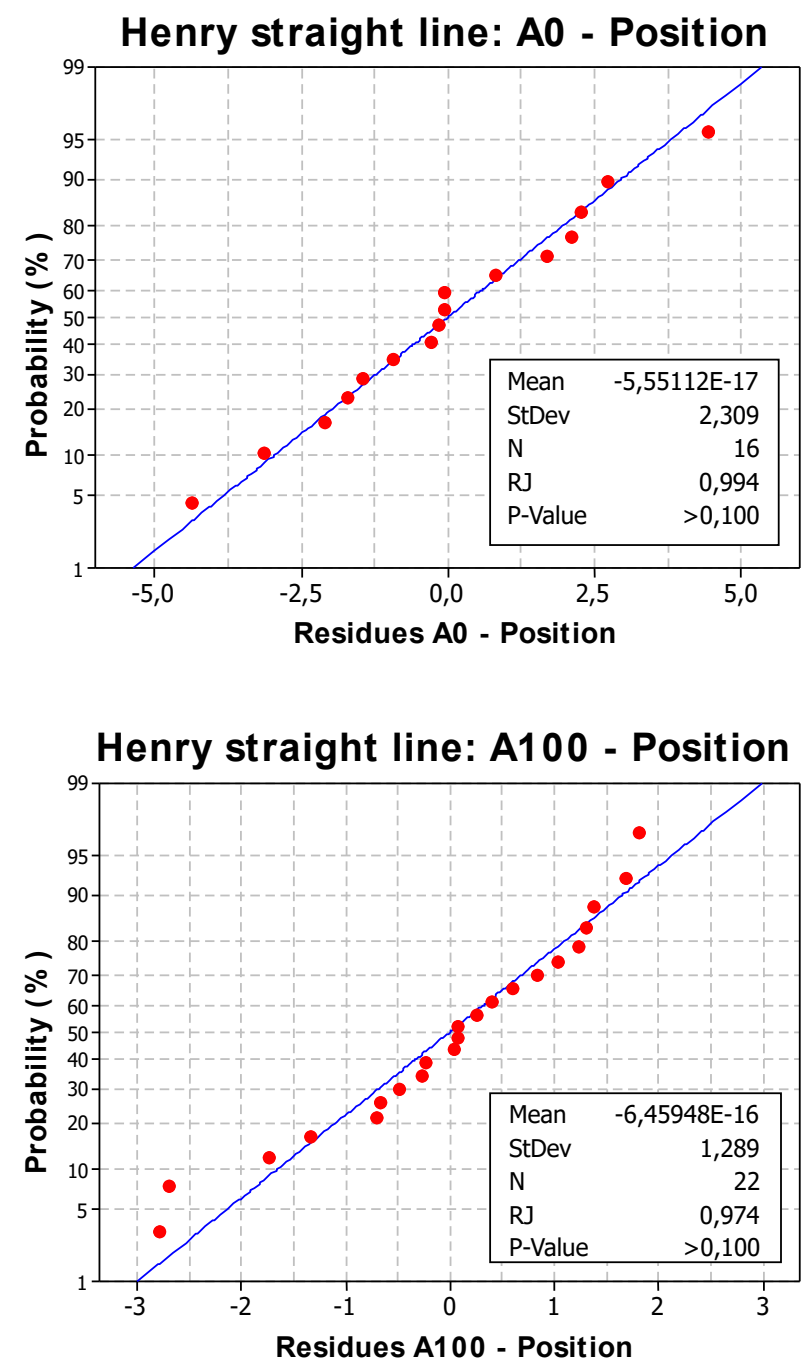

Henry straight line: A50 - Position

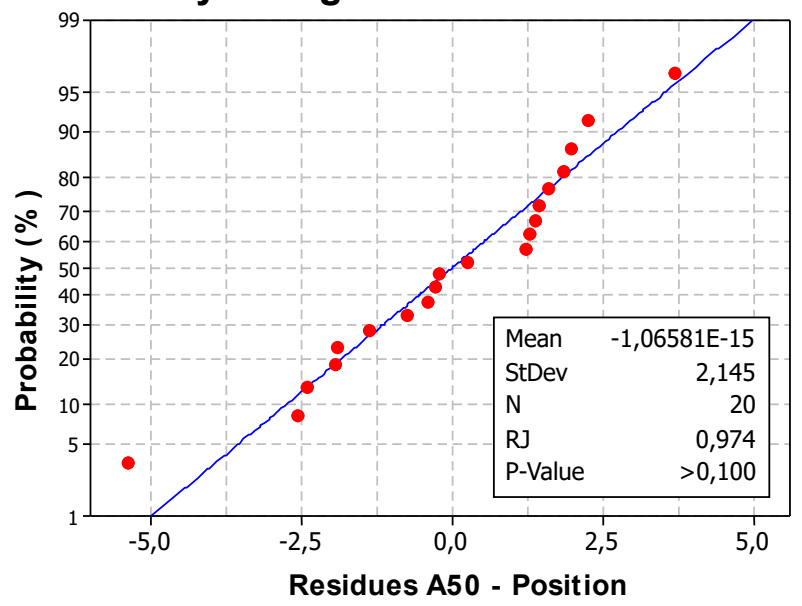


(b) System factor
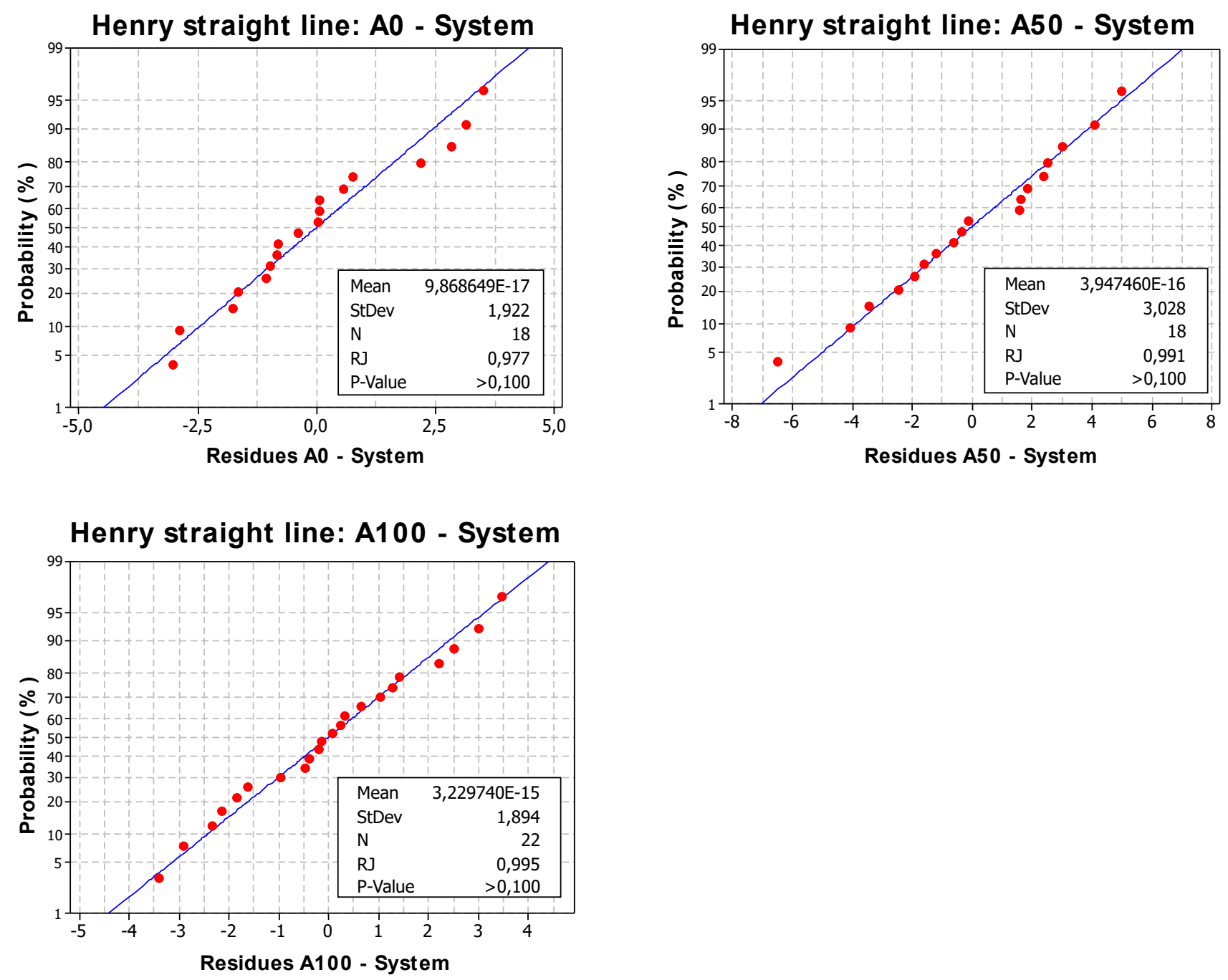
(c) Analyst factor
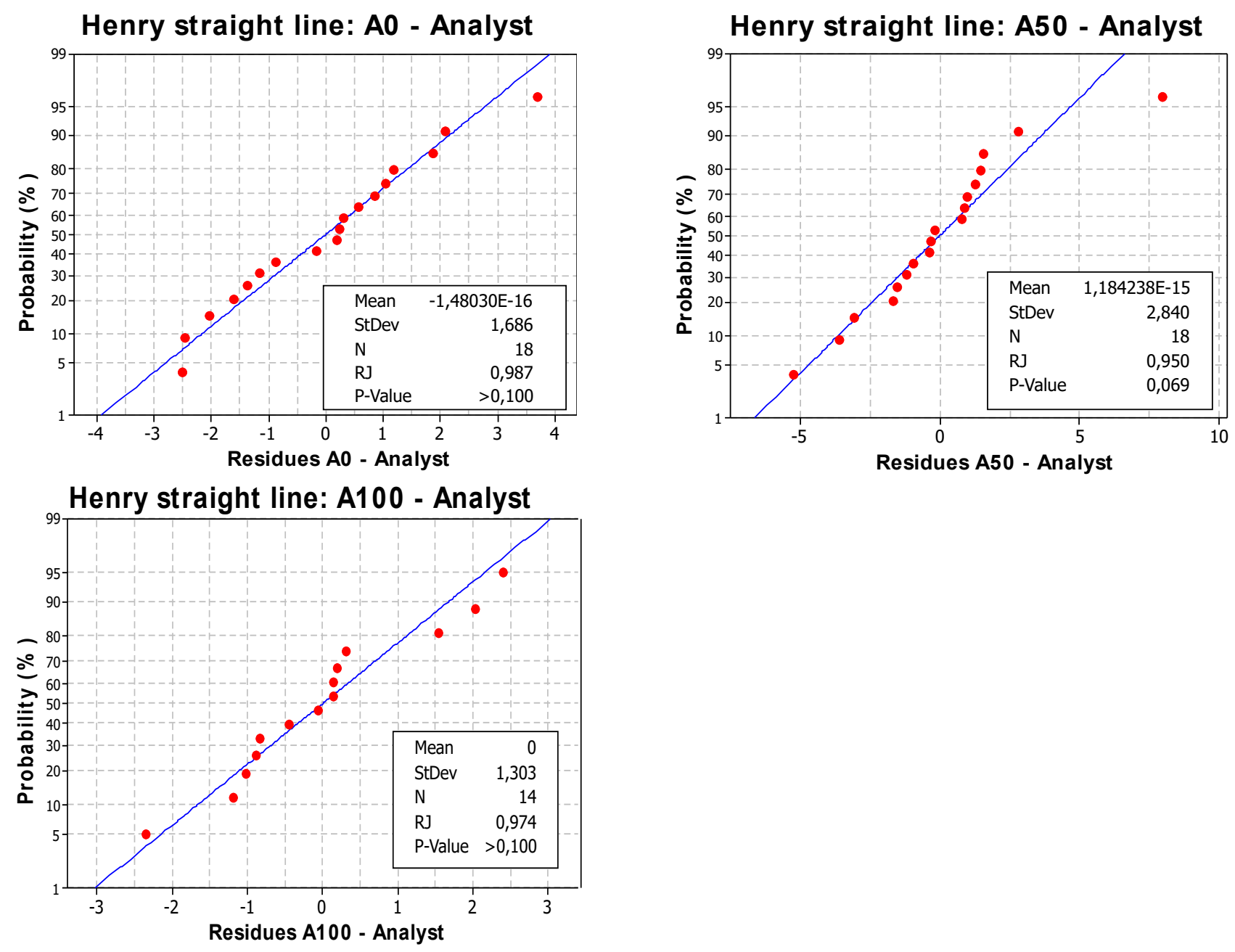


\section{(d) Sample preparation factor}
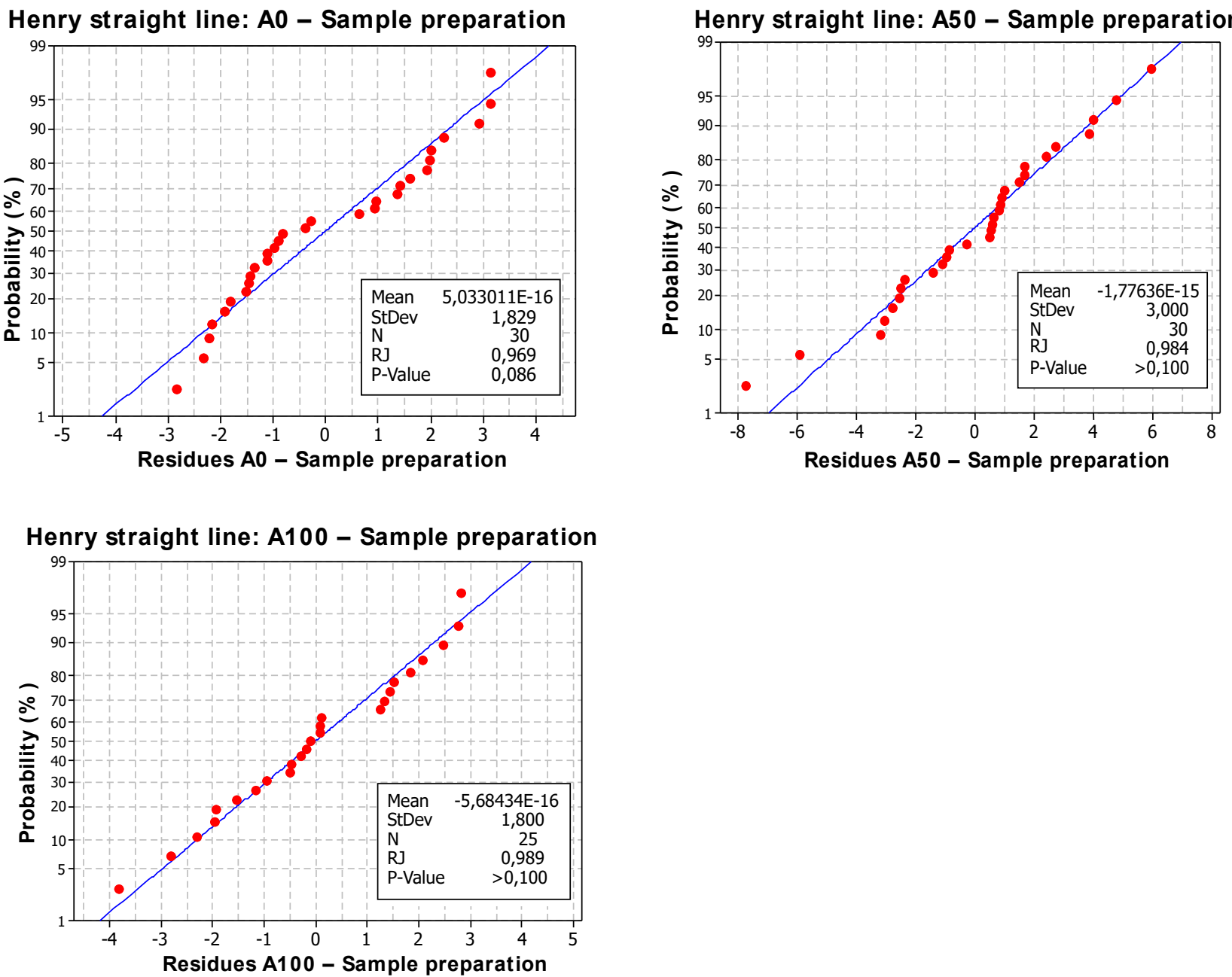
(e) Day factor
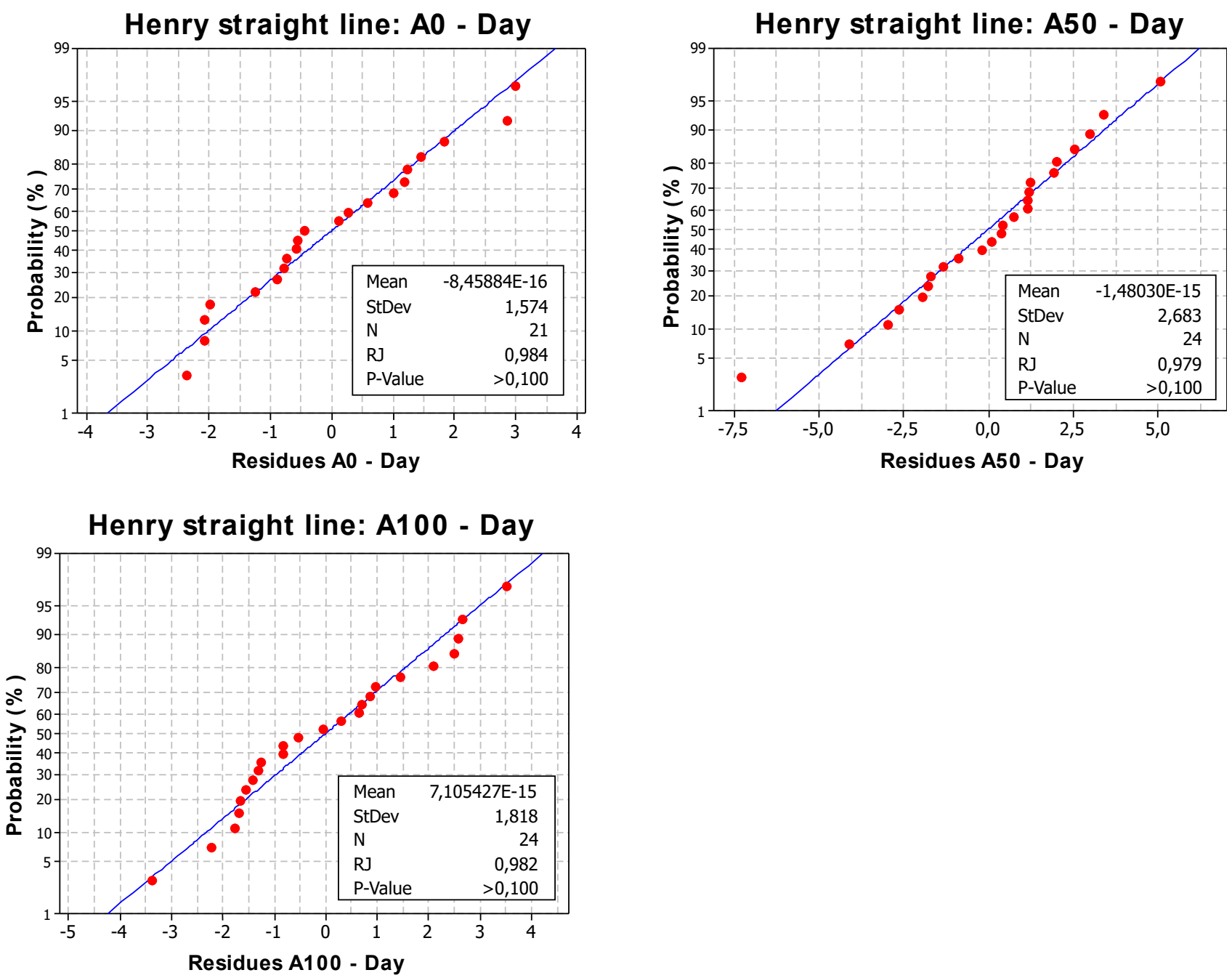

S3-B: Robustness study - Results for Levene's test

\begin{tabular}{cccc}
\hline \multirow{2}{*}{ Factor } & \multicolumn{3}{c}{ Levene's test p-value } \\
\hline & $\mathrm{A} 0$ & $\mathrm{~A} 50$ & $\mathrm{~A} 100$ \\
\hline Position & 0.461 & 0.772 & 0.926 \\
\hline System & 0.296 & 0.461 & 0.711 \\
\hline Analyst & 0.135 & 0.312 & 0.146 \\
\hline Sample preparation & 0.156 & 0.449 & 0.384 \\
\hline Day & 0.814 & 0.169 & 0.300
\end{tabular}

